\title{
Impact of technical innovation on surgical outcome of laparoscopic major liver resection: 10 years' experience at a large-volume center
}

\author{
Wontae Cho', Choon Hyuck David Kwonn ${ }^{2,3}$, Jin Yong Choi ${ }^{4}$, Seung Hwan Lee ${ }^{5}$, Jong Man Kim², Gyu Seong Choi ${ }^{2}$, \\ Jae-Won Joh', Sung Joo Kim², Gaab Soo Kim ${ }^{6}$, Kwang Chul Koh ${ }^{7}$ \\ ${ }^{1}$ Department of Surgery, Hallym University Medical Center, Dongtan Sacred Heart Hospital, Seoul, Korea \\ ${ }^{2}$ Department of Surgery, Samsung Medical Center, Sungkyunkwan University School of Medicine, Seoul, Korea \\ ${ }^{3}$ Department of General Surgery, Cleveland Clinic, Cleveland, OH, USA \\ ${ }^{4}$ Department of Surgery, Soonchunhyang University Seoul Hospital, Seoul, Korea \\ ${ }^{5}$ Department of Surgery, Kyung Hee University Medical Center at Gangdong, Seoul, Korea \\ ${ }^{6}$ Department of Anesthesiology and Pain Medicine, Samsung Medical Center, Sungkyunkwan University School of Medicine, \\ Seoul, Korea \\ ${ }^{7}$ Department of Medicine, Samsung Medical Center, Sungkyunkwan University School of Medicine, Seoul, Korea
}

\begin{abstract}
Purpose: Laparoscopic major liver resection (major LLR) remains a challenging procedure because of the technical difficulty. Several significant technical innovations have been applied in our center since 2012. They include routine application of bipolar electrocautery, initiation of temporary increase of intra-abdominal pressure during bleeding events from veins to balance the central venous pressure, and use of temporary inflow control of the Glissonean pedicle. This study evaluated the impact of these technique modifications in patients with major LLR.

Methods: Between January 2004 and February 2015, a total of 606 patients underwent LLR at Samsung Medical Center in Seoul, Korea. Major LLR was employed in 233 cases. All major LLR procedures were anatomical resections performed with a totally laparoscopic approach. We compared surgical parameters of right hepatectomy (RH), left hepatectomy (LH), and right posterior sectionectomy (RPS) before and after 2012.

Results: Open conversion rates of RH and LH and estimated blood loss in RPS significantly decreased after 2012. The postoperative complication rate of major LLR was $12.7 \%$ and was similar before and after 2012 . Bile leakage was the most common complication (3.2\%).

Conclusion: The modifications of surgical techniques resulted in good outcomes for laparoscopic major LLR. We recommend routine application of these techniques to improve outcomes, especially in patients requiring major liver resection.

[Ann Surg Treat Res 2019;96(1):14-18]
\end{abstract}

Key Words: Laparoscopy, Hepatectomy, Minimally invasive surgical procedures, Learning curve

Received May 24, 2018, Revised July 18, 2018, Accepted July 24, 2018

Corresponding Author: Choon Hyuck David Kwon

Department of Surgery, Samsung Medical Center, Sungkyunkwan University School of Medicine, 81 Irwon-ro, Gangnam-gu, Seoul 06351, Korea

Tel: +82-2-3410-1281, Fax: +82-2-3410-0040

E-mail: chdkwon@gmail.com

ORCID code: https://orcid.org/0000-0002-1082-3321
Copyright (c) 2019, the Korean Surgical Society

(c) Annals of Surgical Treatment and Research is an Open Access Journal. All articles are distributed under the terms of the Creative Commons Attribution NonCommercial License (http://creativecommons.org/licenses/by-nc/4.0/) which permits unrestricted non-commercial use, distribution, and reproduction in any medium, provided the original work is properly cited. 


\section{INTRODUCTION}

Unlike the widespread use of laparoscopic cholecystectomy after its introduction in clinical practice, the application of laparoscopic liver resection (LLR) has displayed little progress in terms of clinical adoption since the first case was performed two decades ago. The slow acceptance of the laparoscopic approach in liver resection is believed to be primarily due to the technical difficulty of the operation [1]. Recently, with development of new surgical instruments and the ongoing accumulation of surgical experience, LLR is rapidly becoming recognized as a procedure that can decrease morbidity and shorten length of hospital stay [2]. Nevertheless, major LLR remains a challenging procedure and has been performed only in a few experienced centers, so there is limited data available to evaluate the perioperative outcomes [3].

LLR was initiated in 2004 at our center, with the first procedures mostly tumorectomies or left lateral sectionectomies [4]. In 2012, we made several major technical changes, including routine use of bipolar electrocautery, application of a temporary increase of intra-abdominal pressure (IAP) during bleeding events from veins to balance the central venous pressure (CVP), and employment of a new technique called temporary inflow control of the Glissonean pedicle (TICGL) [5]. As a result, we have been able to perform major LLR procedures more frequently in recent years.

The purposes of this study were to compare surgical parameters before and after 2012 and to evaluate the impact of these changes in the performance of major LLR.

\section{METHODS}

\section{Patients and data collection}

Between January 2004 and February 2015, a total of 606 consecutive patients underwent LLR at Samsung Medical Center in Seoul, Korea. This study was cleared with the Institutional Review Board of Samsung Medical Center (SMC 2018-04-072001).

There were 233 cases requiring major LLRs, following the exclusion of 39 cases of living donor hepatectomy. Although right posterior sectionectomy (RPS) is not commonly included under the umbrella of major hepatectomy, we included it in this study since the procedure is as difficult to perform as right hepatectomy $(\mathrm{RH})$ or left hepatectomy $(\mathrm{LH})$, especially via the laparoscopic approach [6]. In addition, there were 12 cases of right anterior sectionectomy (RAS) and central hepatectomy (CH) performed after 2012 [7]. However, since there was only one case of RAS and no cases of $\mathrm{CH}$ completed prior to 2012, we excluded these operations due to the perceived difficulty of comparison.

We reviewed the perioperative clinical outcomes of a total of 220 cases, which were divided before-2012 and after-2012 groups, to evaluate the impact of the changes in surgical procedure. We compared operation time, estimated blood loss, hospital stay, open conversion rate, intraoperative transfusion rate, and complication rate according to operation type. Postoperative complications were classified by Clavien-Dindo classification. All LLR procedures were performed using a total laparoscopic approach.

\section{Operative procedures}

For surgery, each patient was placed in the French position. Pneumoperitoneum was created by carbon dioxide insufflation at a pressure of $11 \mathrm{mmHg}$ to $12 \mathrm{mmHg}$. IAP was increased up to $15-18 \mathrm{mmHg}$ at the time of major vessel bleeding. Superficial parenchymal transection was performed using advanced bipolar device (Thunderbeat(r); Olympus, Tokyo, Japan) or ultrasonic shears (Sonicision(R); Medtronic, Minneapolis, MN, USA). Slow closure of jaw with pressing energy button of the instrument methods were used to prevent small vessel bleeding. Cavitron Ultrasonic Surgical Aspirator (CUSA) was used for deep area dissection. Vessels measuring larger than $5 \mathrm{~mm}$ were divided using a stapler, while vessels of $2 \mathrm{~mm}$ to $5 \mathrm{~mm}$ in size were clipped. Bleeding from the parenchyma dissected area was controlled using bipolar electrocautery with frequent suction. Intraoperative ultrasound was used to determine the locations of tumor and vascular structures. The use of portal triad clamping (Pringle maneuver) was not applied routinely, but it was used liberally when there was a significant amount of blood loss or when a long operation time was expected. Prior to 2012, we primarily used an individual ligation technique by the conventional approach. After-2012, the anterior approach and Glissonean approach were predominantly employed. The TICGL technique consists of (1) temporary application of a bulldog clamp on the corresponding Glissonean pedicle without total ligation or division, (2) transection of the liver parenchyma by controlled hepatectomy, (3) division of the Glisson pedicle under full exposure of the Glissonean branch, and (4) finalization of parenchymal transection [5]. This method provides safe stapling of the Glissonean branch and is easy and quick to apply, which has made anatomical liver resection much more feasible and has therefore been applied routinely since 2012. The specimen was extracted through a Pfannenstiel incision.

\section{Statistical analyses}

Chi-square and Fisher exact tests were used to compare categorical variables. Student t-test and the Mann-Whitney U-test were used for continuous variables. Statistical significance was defined as $\mathrm{P}<0.05$. PASW Statistics 18.0 for Windows (SPSS Inc., Chicago, IL, USA) was used for analysis. 


\section{RESULTS}

There were 44 major LLRs performed before 2012 and 176 cases after 2012. The proportions of RH and LH were similar before 2012, but RH was dominant after 2012 (Table 1). The clinical characteristics of major LLR are shown in Table 2. After 2012, background hepatocellular carcinoma was more common, ICG15 was higher, and patients were older compared with before $2012(\mathrm{P}<0.05)$.

Table 3 shows the surgical parameters according to operation type and period. The total open conversion rate of major LLR was $10.3 \%$. The open conversion rate was decreased in both $\mathrm{RH}$ and LH, while there were no differences in the other surgical parameters. Estimated blood loss was decreased in RPS after 2012, but open conversion rate had no statistical difference before and after 2012. Hospital stay in RPS was increased after 2012.

The overall postoperative complication rate of major LLR was $12.7 \%$, and there were no statistical differences between the two periods. The Clavien-Dindo classification of postoperative complications is shown in Table 4. Bile leakage was the most

Table 1. Type of operation between the 2-time periods in major liver resection

\begin{tabular}{lrc}
\hline \multicolumn{1}{c}{ Type of operation } & $\begin{array}{c}\text { Before 2011 } \\
(\mathrm{n}=44)\end{array}$ & $\begin{array}{c}\text { After 2012 } \\
(\mathrm{n}=176)\end{array}$ \\
\hline Right hepatectomy & $20(44.4)$ & $86(45.7)$ \\
Left hepatectomy & $19(42.2)$ & $54(28.7)$ \\
Right posterior sectionectomy & $5(11.1)$ & $36(19.1)$ \\
\hline
\end{tabular}

Values are presented as number (\%). common complication (3.2\%). One patient in the after-2012 group required reoperation, and percutaneous drainage was necessary in one patient from each group. One patient in the after-2012 group showed a persistent increase of bilirubin with a large amount of ascites after RH. The patient had alcoholrelated cirrhosis patient with a large tumor $(6.6 \mathrm{~cm}$ in diameter $)$ and showed nonspecific preoperative laboratory data (e.g., Child A, ICG I $_{15}$ 10.0\%; PT [INR]: 1.14; platelet count: $216 \times 10^{3} / \mu \mathrm{L}$ ). We recommended liver transplantation, but he was lost during follow-up. There was no mortality in the perioperative period.

\section{DISCUSSION}

Major LLR is a challenging procedure that requires expertise, and its performance is limited to only a few institutions because of its inherent technical difficulties. The second Consensus Meeting in Morioka stated that major LLR comprises innovative procedures in the exploration phase [8]. However, the demand of major LLR is increasing because of doctor needs and patient desire for minimally invasive surgery.

We continuously aimed our procedures toward improving the surgical outcomes of major LLR. Throughout the 10 years of LLR experiences as a large-volume center, many technical innovations have been attempted at our institution. Among them, some major changes were completed at the end of 2011, which included routine application of bipolar electrocautery, application of an increase in IAP during bleeding events from veins to balance the CVP, and use of the TICGL method. As a result, the percentage of cases performed with the laparoscopic approach, and the proportion of major LLR procedures has steadily increased. Major LLR operations, which accounted for

Table 2. Clinical characteristics of major laparoscopic liver resection

\begin{tabular}{|c|c|c|c|}
\hline \multirow{2}{*}{ Characteristic } & \multicolumn{2}{|c|}{ Major hepatectomy $(n=220)$} & \multirow{2}{*}{ P-value } \\
\hline & Before $2011(n=44)$ & After $2012(n=176)$ & \\
\hline Age (yr), median (range) & $51(19-70)$ & $57(23-81)$ & 0.042 \\
\hline Sex, male:female, n (\%) & 29 (64.4):15 (35.5) & $118(54.1): 58(26.6)$ & 0.891 \\
\hline Body mass index $\left(\mathrm{kg} / \mathrm{m}^{2}\right)$, mean (range) & $22.4(17.0-31.2)$ & $23.7(19.0-30.7)$ & 0.394 \\
\hline $\mathrm{ICG}_{15}(\%)$, mean $\pm \mathrm{SD}$ & $8.39 \pm 4.17$ & $11.32 \pm 6.18$ & 0.023 \\
\hline Liver cirrhosis & $8(18.2)$ & $50(28.4)$ & 0.187 \\
\hline \multicolumn{4}{|l|}{ Child-Pugh class, n (\%) } \\
\hline A & $44(100)$ & $174(98.8)$ & 0.481 \\
\hline $\mathrm{B}$ & $0(0)$ & $2(1.2)$ & \\
\hline \multicolumn{4}{|l|}{ Etiology, n (\%) } \\
\hline Hepatocellular carcinoma & $15(34.1)$ & $135(76.7)$ & 0.026 \\
\hline Tumor size $(\mathrm{cm})$, mean $\pm \mathrm{SD}$ & $3.42 \pm 1.90$ & $3.66 \pm 2.41$ & 0.609 \\
\hline Benign disease $^{\mathrm{a})}$ & $21(47.7)$ & $22(12.5)$ & 0.035 \\
\hline Other malignancy $^{\text {b) }}$ & $8(18.1)$ & $31(17.6)$ & 0.931 \\
\hline
\end{tabular}

$\mathrm{SD}$, standard deviation.

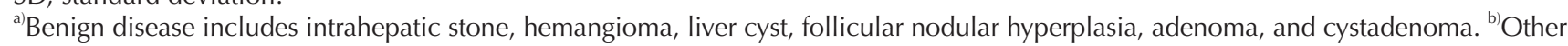
malignancy includes liver metastasis, cholangiocarcinoma, and sarcoma. 


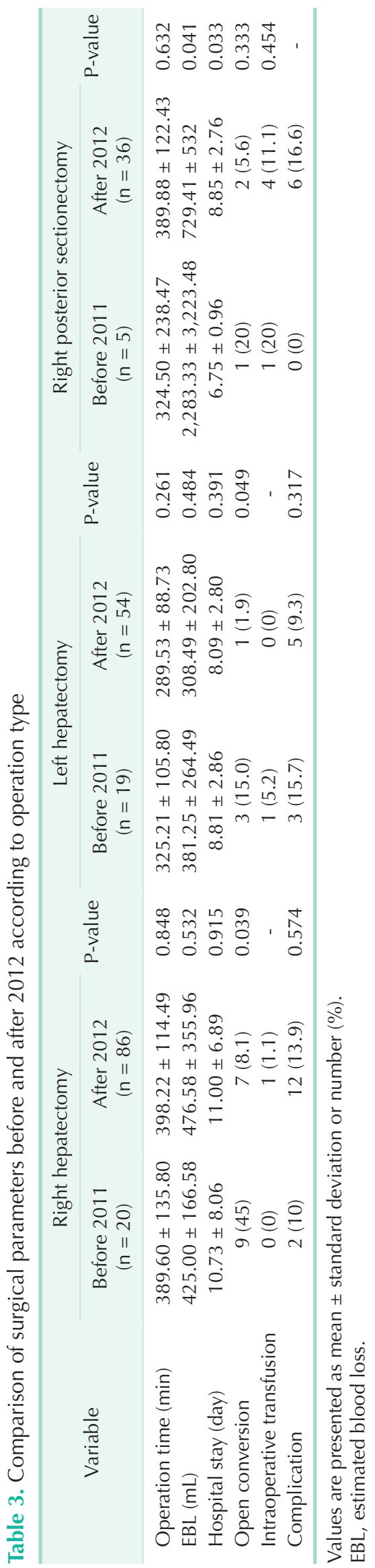

Table 4. Clavien-Dindo classification of postoperative complications $(\mathrm{n}=28)$

\begin{tabular}{ccc}
\hline $\begin{array}{c}\text { Clavien-Dindo } \\
\text { classification }\end{array}$ & $\begin{array}{c}\text { Before 2011 } \\
(\mathrm{n}=5,11.3 \%)\end{array}$ & $\begin{array}{c}\text { After 2012 } \\
(\mathrm{n}=23,13.1 \%)\end{array}$ \\
\hline I & $3(6.7)$ & $7(3.9)$ \\
II & $1(2.2)$ & $9(5.1)$ \\
IIIa & $1(2.2)$ & $3(1.7)$ \\
IIIb & - & $2(1.1)$ \\
IVa & - & $2(1.1)$ \\
IVb & - & - \\
V & - & - \\
\hline
\end{tabular}

Values are presented as number (\%).

about $15 \%$ before 2012 , now constitute about $50 \%$ of the whole program after 2012 (data not shown).

The most common cause of open conversion during major LLR is main hepatic vein injury. The hepatic vein is easily injured by blind dissection of the parenchyma using advanced bipolar devices or ultrasonic shears. Therefore, we used a CUSA in the deep areas around the hepatic vein. It is important to keep the area of dissection dry by constant use of bipolar electrocautery to enhance the precision of dissection. Countertraction and lift-up of the liver by an experienced first assistant also help to limit blood loss, especially in RPS. When the liver is lifted, the right hepatic vein can be rotated anteriorly to the inferior vena cava, and net central and hepatic venous pressure can be reduced [7]. Therefore, even though operation time may be longer, as shown in the RH and RPS groups, conversion due to troublesome bleeding may be reduced (from $45 \%$ to $8.1 \%$ in $\mathrm{RH}$ and from $20 \%$ to $5.6 \%$ in RPS).

The concomitant use of increased IAP to balance the CVP during venous injury is also an important reason for decreased conversion and transfusion rate. The well-balanced increase of IAP decreased the bleeding amount from veins and helped to ensure the availability of more time to repair the injury. To date, we have not encountered any clinical deterioration caused by gas embolism among our patients, contrary to common belief and fears. The coordination of an anesthesiologist to reduce CVP during surgery is also vital.

The use of the TICGL method facilitates more precise and safe liver parenchymal transection. Selective clamping of the pedicle using TICGL enables controlled hepatectomy under inflow occlusion and reduces blood loss. Moreover, because the stapling is performed after a large portion of the parenchyma is dissected and the Glissonean branches are exposed, it has high safety and prevents injury of the remnant branches, which may be a major problem in cases with anatomical variations. It is also less technically demanding with a reduced chance of bleeding.

The surgical results shown in this study were not inferior compared to the findings of other international multicenter 
studies [9,10], and our intraoperative transfusion and complication rates were low versus those of another multicenter study from Korea [11]. Our postoperative complications rate was lower than those reported on open resection, possibly partly due to the selection process we employed for the laparoscopic approach. This theory, however, is beyond the scope of this study and needs additional comparative data analysis to establish conclusively. Nevertheless, there are reports that indicate that laparoscopy is associated with a lower incidence of postoperative morbidity [12]. Bile leakage was the most common complication in our study, as it was in previous other studies [13,14], and is the main problem to solve.

The major LLR procedures in this study were performed by a total of three surgeons and mainly using protocolized procedures. All participating surgeons tried to use the pre- viously noted surgical techniques. There were no differences between the surgeons in terms of surgical outcome. The limitation of this study is its lack of oncological outcome of LLR, because we focused on early postoperative outcomes. We can analyze these outcomes in the near future.

In conclusion, the surgical innovations employed in this study offered good results in patients requiring major liver resection. With the application of these techniques, major LLR may be performed more widely and safely.

\section{CONFLICTS OF INTEREST}

No potential conflict of interest relevant to this article was reported.

\section{REFERENCES}

1. O'Rourke N, Fielding G. Laparoscopic right hepatectomy: surgical technique. J Gastrointest Surg 2004:8:213-6.

2. Vibert E, Perniceni T, Levard H, Denet C, Shahri NK, Gayet B. Laparoscopic liver resection. Br J Surg 2006;93:67-72.

3. Buell JF, Cherqui D, Geller DA, O'Rourke $\mathrm{N}$, Iannitti D, Dagher I, et al. The international position on laparoscopic liver surgery: The Louisville Statement, 2008. Ann Surg 2009:250:825-30.

4. Lee GC, Kwon CH, Joh JW, Heo JS, Jung GO, Moon JI, et al. Preliminary experience of laparoscopic hepatectomy for hepatocellular carcinoma. Korean J Hepatobiliary Pancreat Surg 2011;15:7-12.

5. Lee N, Cho CW, Kim JM, Choi GS, Kwon $\mathrm{CH}$, Joh JW. Application of temporary inflow control of the Glissonean pedicle method provides a safe and easy technique for totally laparoscopic hemihepatectomy by Glissonean approach. Ann Surg Treat Res 2017;92:383-6.
6. Ban D, Tanabe M, Ito H, Otsuka Y, Nitta $\mathrm{H}$, Abe $\mathrm{Y}$, et al. A novel difficulty scoring system for laparoscopic liver resection. J Hepatobiliary Pancreat Sci 2014:21:745-53.

7. Cho CW, Rhu J, Kwon CHD, Choi GS, Kim JM, Joh JW, et al. Short-term outcomes of totally laparoscopic central hepatectomy and right anterior sectionectomy for centrally located tumors: a case-matched study with propensity score matching. World J Surg 2017;41:2838-46.

8. Wakabayashi G, Cherqui D, Geller DA, Buell JF, Kaneko H, Han HS, et al. Recommendations for laparoscopic liver resection: a report from the second international consensus conference held in Morioka. Ann Surg 2015;261:619-29.

9. Dagher I, Gayet B, Tzanis D, Tranchart H, Fuks D, Soubrane O, et al. International experience for laparoscopic major liver resection. J Hepatobiliary Pancreat Sci 2014:21:732-6.

10. Dagher I, O'Rourke N, Geller DA, Cherqui
D, Belli G, Gamblin TC, et al. Laparoscopic major hepatectomy: an evolution in standard of care. Ann Surg 2009;250:85660.

11. Hwang DW, Han HS, Yoon YS, Cho JY, Kwon Y, Kim JH, et al. Laparoscopic major liver resection in Korea: a multicenter study. J Hepatobiliary Pancreat Sci 2013;20:125-30.

12. Aldrighetti L, Guzzetti E, Pulitanò C, Cipriani F, Catena M, Paganelli M, et al. Case-matched analysis of totally laparoscopic versus open liver resection for HCC: short and middle term results. J Surg Oncol 2010;102:82-6.

13. Nomi T, Fuks D, Govindasamy M, Mal F, Nakajima Y, Gayet B. Risk factors for complications after laparoscopic major hepatectomy. Br J Surg 2015;102:254-60.

14. Nomi T, Fuks D, Kawaguchi Y, Mal F, Nakajima Y, Gayet B. Learning curve for laparoscopic major hepatectomy. Br J Surg 2015;102:796-804. 